\title{
Determination of Cobalt in Seawater Using Neutron Activation Analysis after Preconcentration by Adsorption onto $\gamma-\mathrm{MnO}_{2}$ Nanomaterial
}

\author{
Van-Phuc Dinh (iD, ${ }^{1}$ Ngoc-Chung Le, ${ }^{2}$ Ngoc-Tuan Nguyen, ${ }^{3}$ \\ Quang-Thien Tran, ${ }^{3}$ Van-Dong Nguyen, ${ }^{4}$ Anh-Tuyen Luu, ${ }^{5}$ N. Quang Hung, ${ }^{6}$ \\ Tran Duy Tap, ${ }^{4}$ and Thien-Hoang Ho ${ }^{1}$ \\ ${ }^{1}$ Dong Nai University, 4 Le Quy Don, Tan Hiep Ward, Bien Hoa City, Dong Nai Province, Vietnam \\ ${ }^{2}$ Dalat University, Dalat City, Lam Dong Province, Vietnam \\ ${ }^{3}$ Nuclear Research Institute, Dalat City, Lam Dong Province, Vietnam \\ ${ }^{4}$ University of Science, Vietnam National University, Ho Chi Minh City, Vietnam \\ ${ }^{5}$ Center for Nuclear Techniques, Vietnam Atomic Energy Institute, Ho Chi Minh City, Vietnam \\ ${ }^{6}$ Institute of Fundamental and Applied Sciences, Duy Tan University, 3 Quang Trung, Da Nang City, Vietnam \\ Correspondence should be addressed to Van-Phuc Dinh; dinhvanphuc82@gmail.com
}

Received 14 September 2017; Revised 4 January 2018; Accepted 28 January 2018; Published 22 February 2018

Academic Editor: Jean-Marie Nedelec

Copyright (C) 2018 Van-Phuc Dinh et al. This is an open access article distributed under the Creative Commons Attribution License, which permits unrestricted use, distribution, and reproduction in any medium, provided the original work is properly cited.

\begin{abstract}
The $\gamma-\mathrm{MnO}_{2}$ nanomaterial has been used to adsorb cobalt in the seawater at Phan Thiet City, Binh Thuan Province, Vietnam. Its concentration is determined by using the neutron activation analysis (NAA) method at the Dalat nuclear research reactor. Factors affecting the uptake of cobalt on the $\gamma-\mathrm{MnO}_{2}$ material such as the $\mathrm{pH}$, adsorption time, and initial cobalt(II) concentration are investigated. The irradiated experiment data are calculated using the K0-Dalat program. The results obtained show that the trace dissolved cobalt in Phan Thiet seawater is found equal to $0.25 \pm 0.04 \mu \mathrm{g} / \mathrm{L}(n=5, P=95 \%)$ with the adsorption efficiency being higher than $95 \%(n=4, P=95 \%)$.
\end{abstract}

\section{Introduction}

Cobalt is an essential micronutrient and the central metal cofactor in the Vitamin $B_{12}$ [1]. It can be found in the biological and environmental samples, such as fish, egg, milk, green vegetable, and seawater. In seawater, dissolved cobalt (DCo) exists mainly as a cobalt(II) ion in chlorocarbonate complexes [2] and bound to organic ligands [3]. Although the concentration of DCo in seawater is rather low, it can affect the growth rate of coccolithophorids and cyanobacteria, some metabolic processes, the phytoplankton community structure, and the carbon flux at the atmosphereocean interface [4]. In addition, the concentration of DCo in seawater, which can vary differently depending on the human activities at different ocean regions such as dust, mineral activity, and industry, can lead to the unpredictable effects on environment and food resources. Therefore, determination of the DCo concentration in seawater has recently become an important topic for interdisciplinary researches including physics, chemistry, and environment. However, it is difficult to determine directly the total DCo in seawater by the most commonly used instrumental analytical methods due to their limited sensitivity and/or matrix effects. Therefore, the separation of cobalt from the sample matrices as well as the preconcentration of cobalt is crucial for the accurate and efficient determinations of cobalt at the ultratrace levels in seawater. Various methods in addition to the modern instrumental methods have been used to enrich the level of cobalt in seawater, such as the coprecipitation [2], liquidliquid phase extraction [5], and solid phase extraction $[6,7]$. 
Neutron activation analysis (NAA) is a sensitive and special method for determining simultaneously a large number of elements [8]. One of the advantages of the NAA method over the common spectrometric methods is that it allows us to directly analyze the samples in original forms without the use of dissolution steps that may cause the sample dilution and contamination. Within the NAA, the preconcentration of the trace elements from the aqueous samples such as seawater absorbed on solid materials is usually preferred among the other methods. However, a drawback of this method is that it is not able to analyze the water samples since the radiolysis of water itself may cause a release of radiogas or even an explosion out of the container [9]. Hence, the adsorption used to preconcentrate the elements from the water onto the solid phase is a promising method for the detection of trace elements in seawater as well as in other solutions. Some adsorbents have been used for these preconcentration steps such as the magnesium oxide [9], charcoal [10-14], and aluminium and iron(III) oxides [15]. However, the use of nanooxide as an adsorbent material for the retention of trace elements from seawater before being determined by the NAA method has still been limited so far.

In fact, the nanomaterials, which have their own physicochemical properties and therefore differ from the nonnanomaterials, have been applied to a variety of areas. Among the nanomaterials, the manganese oxides with various types of crystalline structures, such as $\alpha-, \beta-, \gamma-\mathrm{MnO}_{2}$, have been extensively studied owing to their structural varieties and excellent chemical characteristics. As a result, they have been applied to different areas such as batteries, molecular sieves, catalysts, and adsorbents $[16,17]$. However, the use of $\gamma$ $\mathrm{MnO}_{2}$ nanomaterial as a solid phase for the preconcentration of cobalt from seawater has still been rarely studied.

In the present work, the $\gamma-\mathrm{MnO}_{2}$ nanomaterial is used as a preconcentration agent to extract cobalt from the seawater collected at Hon Rom Beach, Phan Thiet City, Binh Thuan Province, Vietnam, before applying the NAA method to determine its concentration. Furthermore, factors affecting the adsorption capacity of this nanomaterial such as the $\mathrm{pH}$, adsorption time, and initial cobalt concentration are also investigated within the present work.

\section{Experimental Method}

2.1. Reagents and Materials. The cobalt(II) ion is used as an adsorbate. A $1000 \mathrm{mg} / \mathrm{L}$ standard stock solution containing each set of cobalt(II) ions is prepared by dissolving the $\mathrm{Co}\left(\mathrm{NO}_{3}\right)_{2}$ (Merck, pa) in the double-distilled water. The $\mathrm{HNO}_{3}$ (Merck, pa) and $\mathrm{NaOH}$ (Merck, pa) are then used to adjust the $\mathrm{pH}$ of the solution. The $\gamma-\mathrm{MnO}_{2}$ nanomaterial is synthesized via the reaction between the potassium permanganate $\left(\mathrm{KMnO}_{4}\right)$ (Merck, pa) solution and the ethanol $\left(\mathrm{C}_{2} \mathrm{H}_{5} \mathrm{OH}\right)(\mathrm{Merck}, \mathrm{pa})$ at the room temperature as reported previously in $[17,18]$. A $300 \mathrm{ml}$ potassium permanganate $\left(\mathrm{KMnO}_{4}\right)$ saturated solution is gradually placed into a $300 \mathrm{ml}$ of the mixture between the ethanol $\left(\mathrm{C}_{2} \mathrm{H}_{5} \mathrm{OH}\right)$ and the distilled water, which is then strongly agitated during $8 \mathrm{~h}$. The obtained solid precipitate is dried at $100^{\circ} \mathrm{C}$ in $12 \mathrm{~h}$. After that

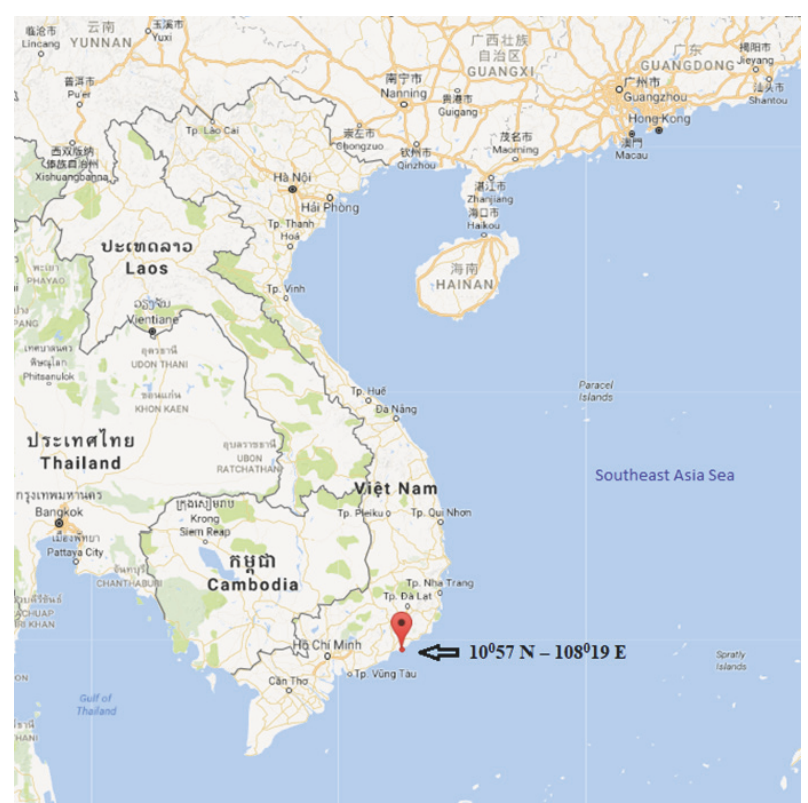

Figure 1: Hon Rom Beach, Phan Thiet City, Binh Thuan Province, Vietnam, where the seawater samples are collected.

it is cleaned several times by using the distilled water in order to get the $\gamma-\mathrm{MnO}_{2}$ products.

Seawater, collected from the Hon Rom Beach, Phan Thiet City, Binh Thuan Province, Vietnam, at the position of $10^{\circ} 57 \mathrm{~N}-108^{\circ} 19 \mathrm{~W}$ (see Figure 1), is filtered through $0.2 \mu \mathrm{m}$ Sartobran 300 cartridges (Sartorius), which are later used for the DCo analyses. The samples are collected in the acid cleaned $250 \mathrm{~mL}$ LDPE Nalgene ${ }^{\circledR}$ bottles, which are rinsed 5 times together with the samples before the collection. After that, the processes are similar to those presented in Section 2 of [19], except that $\mathrm{HNO}_{3}$ at $0.01 \mathrm{M}$ (Merck) has been used to acidify the samples within an hour instead of using ultrapure ${ }^{\circledR}$ $\mathrm{HCl}$ as in [19].

2.2. Instruments. The phase of the crystalline structure is determined by using the X-ray diffractometer (XRD) D5000 made by Siemens (Germany) with the $\mathrm{X}$-ray radiation of $\mathrm{CuK} \alpha$ and wavelength $\lambda=1,5406 \AA$. The ultrahigh resolution scanning electron microscopy (SEM) S-4800 made by Hitachi (Japan) and the transmission electron microscope (TEM) JEM 1010 made by JEOL (Japan) are used to investigate the morphology of the materials. The surface area of the materials is calculated within the Brunauer-Emmett-Teller (BET) theory [26]. The concentration of the samples before and after the adsorption is determined by using the atomic absorption spectrophotometer (AA-7000) made by Shimadzu (Japan). In addition, the $\mathrm{pH}$ measurements are performed using a $\mathrm{pH}$ meter Mi-150 (MARTINI Instruments made in Romania). The latter is standardized using the HANNA instrumental buffer solutions with different values of $\mathrm{pH}$, namely, $4.01 \pm$ $0.01,7.01 \pm 0.01$, and $10.01 \pm 0.01$. A temperature-controlled shaker (Model IKA R5) is used for the studies of the equilibrium states. 
TABLE 1: Isotherm equilibrium parameters calculated from different models.

\begin{tabular}{|c|c|c|c|c|c|c|}
\hline Models & Equations & & Parameters & & RMSE & $\chi^{2}$ \\
\hline Langmuir & $q_{e}=\frac{Q_{\max } \cdot K_{L} \cdot C_{e}}{1+K_{L} \cdot C_{e}}$ & $Q_{\max }(\mathrm{mg} / \mathrm{g}): 90.91$ & & $K_{L}(\mathrm{~L} / \mathrm{mg}): 0.5430$ & 1.999 & 0.2918 \\
\hline Freundlich & $q_{e}=K_{F} \cdot C_{e}^{1 / n}$ & $K_{F}(\log / g): 63.82$ & & $1 / n: 0.0769$ & 2.233 & 0.3418 \\
\hline Sips & $q_{e}=\frac{Q_{S} \cdot C_{e}^{\beta_{S}}}{1+\alpha_{s} \cdot C_{e}^{\beta_{S}}}$ & $Q_{s}(\mathrm{mg} / \mathrm{g}): 95.00$ & $\alpha_{s}(\mathrm{~L} / \mathrm{mg}): 0.9810$ & $\beta_{s}: 0.5694$ & 1.593 & 0.1751 \\
\hline
\end{tabular}

Notations. $q_{e}$ : adsorption capacity at equilibrium $(\mathrm{mg} / \mathrm{g}) ; C_{e}$ : equilibrium concentration $(\mathrm{mg} / \mathrm{L}) ; \mathrm{Q}_{\max }$ : monolayer maximum adsorption capacity $(\mathrm{mg} / \mathrm{g})$; $K_{L}$ : Langmuir constant; $K_{F}$ : Freundlich constant; $n$ : adsorption intensity; $Q_{S}$ : the maximum adsorption capacity $(\mathrm{mg} / \mathrm{g}) ; \alpha_{s}$ : Sips isotherm model constant $(\mathrm{L} / \mathrm{mg}) ; \beta_{s}$ : Sips isotherm model exponent; RMSE: root-mean-square error (RMSE $=\sqrt{\left.(1 /(n-1)) \sum_{n=1}^{n}\left(q_{e, \text { meas }}-q_{e, \text { calc }}\right)^{2}\right)}$; $\chi^{2}$ : nonlinear chi-square test $\left(\chi^{2}=\sum_{n=1}^{n}\left(q_{e, \text { meas }}-q_{e, \text { calc }}\right)^{2} / q_{e, \text { calc }}\right)$.

2.3. Adsorption Study. A 0.1 gram of the nanomaterials is placed into a $100 \mathrm{~mL}$ conical flask containing $50 \mathrm{~mL}$ of the cobalt(II) ions. The influences of $\mathrm{pH}(2-5.5)$, adsorption time (10-240 min), and metal ion concentrations $(40-400 \mathrm{mg} / \mathrm{L})$ on the nanomaterials are also studied. The concentrations of cobalt(II) ions before and after the adsorption process are determined by using the atomic absorption spectroscopy method. The adsorption ability of the $\gamma-\mathrm{MnO}_{2}$ nanomaterial is calculated as [27]

$$
\% \text { Removal }=\frac{\left(C_{o}-C_{e}\right) \times 100 \%}{C_{o}},
$$

whereas the adsorption capacity can be obtained from the mass balance equation for the adsorbent as [27]

$$
q=\frac{\left(C_{o}-C_{e}\right) \times V}{m}
$$

where $q$ is the adsorption capacity $(\mathrm{mg} / \mathrm{g}$ ) at the equilibrium and $C_{o}$ and $C_{e}$ are the initial and equilibrium concentrations $(\mathrm{mg} / \mathrm{L})$, respectively. $V$ is the volume $(\mathrm{L})$ of the solution and $m$ is the mass ( $g$ ) of the adsorbent used. In fact, several adsorption isotherm equations [28] have been applied in the present work in order to assess the adsorption ability of the $\gamma-\mathrm{MnO}_{2}$ materials as well as the nature of the uptake as presented in Table 1.

2.4. Neutron Activation Analysis. A 1-gram $\gamma-\mathrm{MnO}_{2}$ is added to 1.5 liters of seawater and they are mixed by magnetically stirring at the speed of $240 \mathrm{rpm}$ in $120 \mathrm{mins}$. The solid is collected via the filtration process and dried at $80^{\circ} \mathrm{C}$ in 24 hours. An accurate weight of the dried $\gamma-\mathrm{MnO}_{2}$ is packed and sealed in the polyethylene containers and then irradiated in the core of the Dalat nuclear research reactor with the neutron flux of $3.10^{12} \mathrm{n} / \mathrm{cm}^{2} \cdot \mathrm{s}$ in 002010 hours. After 30 days of radioactive decay, the samples are measured during $18000 \mathrm{sec}$ in order to determine the cobalt concentration. To control our experimental method, the standard-addition technique has been used by placing 1.0 gram of $\gamma-\mathrm{MnO}_{2}$ with 1.5 liters of seawater, which contain 10,15 , and $20 \mu \mathrm{g}$ of cobalt standard solution. The time for the added cobalt being equilibriated in seawater is 10 mins at the room temperature. The preparation, irradiation, and decaying and measuring times are kept to be the same as for the above samples.

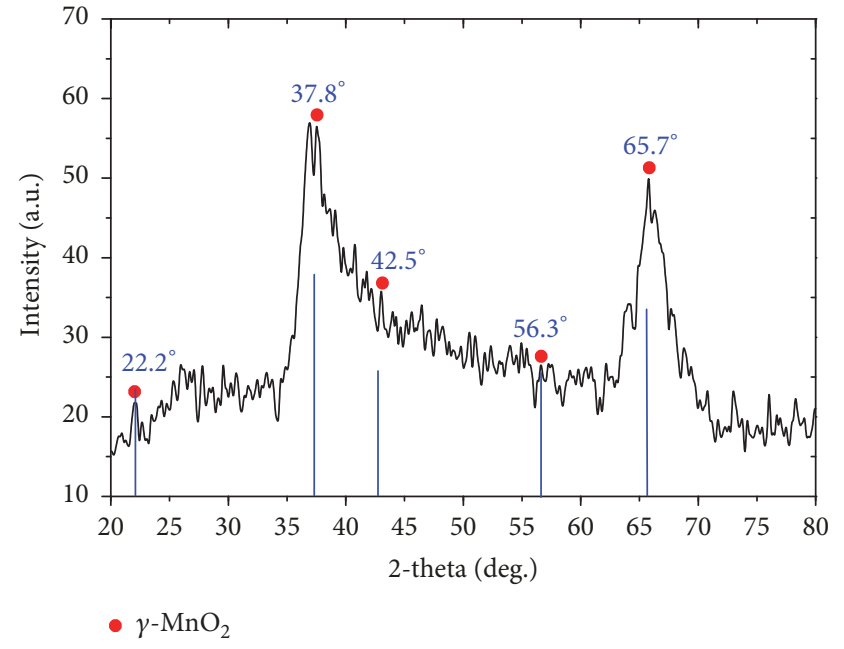

FIgURE 2: The XRD spectrum of the $\gamma-\mathrm{MnO}_{2}$ nanomaterial.

2.5. Gamma Activity Measurement. In order to measure the activated samples, we employ the calibrated gammaray spectrometers based on the HPGe detectors (ORTEC, GMX-30190 model) with the acquisition software provided by CANBERRA Genie-2K. The K0-Dalat program $[29,30]$ is applied to calculate the elemental concentrations, the uncertainties, and the detection limits.

\section{Results and Discussion}

3.1. Characterization of the $\gamma-\mathrm{MnO}_{2}$ Nanomaterial. Shown in Figure 2 are the XRD patterns of the $\gamma-\mathrm{MnO}_{2}$ nanostructure. As can be seen in this Figure 2, some specific peaks are developed at the different angles $2 \theta$ equal to $22.2^{\circ}, 37.8^{\circ}, 42.5^{\circ}$, $56.3^{\circ}$, and $65.7^{\circ}$. These peaks are certainly associated with the orthorhombic structure of the $\gamma-\mathrm{MnO}_{2}$ material (JCPDS card number 82-2169).

Figure 3 presents the SEM (a) and TEM (b) images of $\gamma-\mathrm{MnO}_{2}$. These figures clearly show a porous surface, which includes many nanospheres with diameters from $10 \mathrm{~nm}$ to 80 $\mathrm{nm}$. These results indicate that the $\gamma-\mathrm{MnO}_{2}$ nanomaterial might offer more adsorption sites for the adsorbates.

The surface area and pore size of $\gamma-\mathrm{MnO}_{2}$ are investigated within the BET and Barrett-Joyner-Halenda (BJH) [31] methods. The results obtained are presented in Table 2. It is 
TABLE 2: The BET and BJH analytical results.

\begin{tabular}{lccc}
\hline & BJH Adsorption average pore width & BJH desorption average pore width & BET surface area \\
\hline$\gamma-\mathrm{MnO}_{2}$ & $417.8 \AA$ & $340.2 \AA$ & $65.0 \mathrm{~m}^{2} \cdot \mathrm{g}^{-1}$ \\
\hline
\end{tabular}

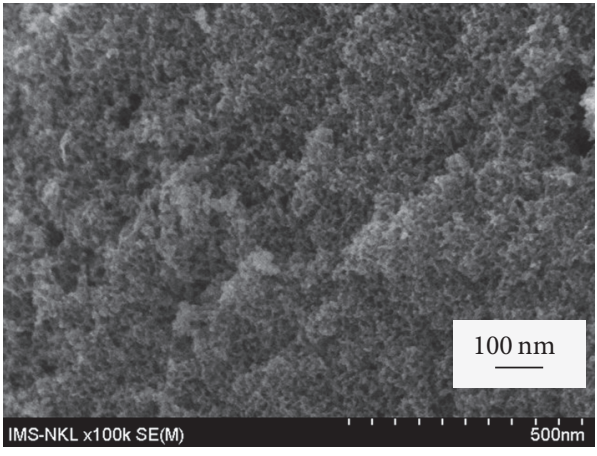

(a)

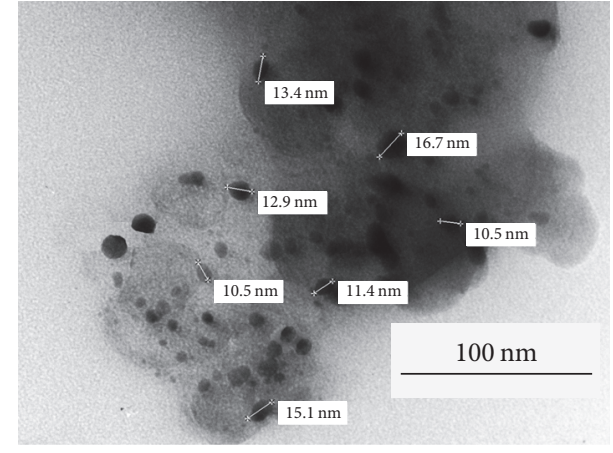

(b)

Figure 3: SEM (a) and TEM (b) images of the $\gamma-\mathrm{MnO}_{2}$ nanomaterial.

seen that the surface area of $\gamma-\mathrm{MnO}_{2}$ is about $65 \mathrm{~m}^{2} / \mathrm{g}$ with a pore size smaller than $500 \AA$ and larger than $20 \AA$, which corresponds to the size of the mesoporous materials [32].

3.2. Factors Affecting the Adsorption of Cobalt. The $\mathrm{pH}$ is one of the essential factors, which affects the adsorption of the cobalt(II) ion onto the $\gamma-\mathrm{MnO}_{2}$ nanomaterials. As can be seen in Figure 4(a), at the low pH values, the uptake of cobalt(II) ion on the material surfaces decreases because of two main reasons. The first reason is due to the charge of the material surface, which is positive and is not favorable for the uptake of $\mathrm{Co}$ (II) cation [33-38]. The second reason is that there is a competition between the $\mathrm{H}^{+}$and $\mathrm{Co}^{2+}$ ions $[37,38]$. At the high $\mathrm{pH}$ values, the adsorption of cobalt(II) ion reaches a plateau due to the formation of different types of cobalt(II) such as $\mathrm{Co}(\mathrm{OH})^{+}$and $\mathrm{Co}(\mathrm{OH})_{2}$, which inhibit the adsorption of $\mathrm{Co}^{2+}$ ions on $\gamma-\mathrm{MnO}_{2}$ [39]. Therefore, a range of $\mathrm{pH}$ values has been chosen from 2.0 to 5.5 in order to achieve the optimum adsorption of cobalt. As a result, the maximum adsorption is obtained at $\mathrm{pH} \geq 4.0$ with an approximate removal of $98.8 \%$ at the initial cobalt concentration of $150 \mathrm{mg} / \mathrm{L}$.

The effects of $\mathrm{pH}$ and contact time on the adsorption of $\mathrm{Co}$ (II) onto the $\gamma-\mathrm{MnO}_{2}$ nanomaterial are shown in Figures 4(a) and 4(b), respectively. These figures show that the adsorption increases with increasing both the $\mathrm{pH}$ and the contact time and reaches the equilibrium after $120 \mathrm{mins}$ at the $\mathrm{pH}$ value of 4 despite different initial cobalt concentrations. Hence, 120 mins of adsorption time has been chosen for adsorbing cobalt from the seawater samples. Moreover, it can be seen also from these figures that the higher the initial concentration of $\mathrm{Co}(\mathrm{II})$ is, the lower the adsorption rate of $\mathrm{Co}(\mathrm{II})$ onto the $\gamma-\mathrm{MnO}_{2}$ nanomaterial is achieved. This result can be explained by the saturation of the binding-sites of the nanomaterial when the concentration is increasing.

3.3. Adsorption Isotherm Studies. Figure 5 shows the plots of the Langmuir, Freundlich, and Sips nonlinear isotherm models, whose parameters are given in Table 1. It is known that the Langmuir model assumes the uptake of cobalt(II) on the $\gamma-\mathrm{MnO}_{2}$ nanomaterial to be monolayer adsorption. On the other hand, the Freundlich model is based on the assumption that the adsorption of cobalt(II) ions should be with multilayers and there is an interaction between the adsorbate and absorbent. However, both of models above are restricted by the solute concentrations. Therefore, the Sips equation, which combines the Langmuir and Freundlich models, has been proposed in order to describe well the uptake of cobalt(II) onto the $\gamma-\mathrm{MnO}_{2}$ nanomaterial. By comparing the results obtained from the root-mean-square error (RMSE) with the corresponding $\chi^{2}$ values, it is found that the Sips model offers the best fit to experimental data as this model has the smallest RMSE and $\chi^{2}$ values among the other two Langmuir and Freundlich models. The monolayer adsorption and adsorption capacities calculated from the Langmuir and Sips models are $90.91 \mathrm{mg} / \mathrm{g}$ and $95.00 \mathrm{mg} / \mathrm{g}$, respectively. These results indicate that the $\gamma-\mathrm{MnO}_{2}$ nanomaterial can be used as an adsorbent to extract and concentrate the cobalt ions from the water samples.

3.4. Determination of Cobalt in Seawater. Figures 6 and 7 depict the gamma-ray spectra of the $\gamma-\mathrm{MnO}_{2}$ nanomaterial before and after the adsorption of elements in seawater. The results obtained from the analysis of some elements in the surface seawater at Hon Rom Beach, Phan Thiet City $\left(10^{\circ} 57^{\prime}\right.$ North- $108^{\circ} 19^{\prime}$ East), using the NAA method after the preconcentration by adsorption onto the $\gamma-\mathrm{MnO}_{2}$ nanomaterial are presented in Table 3. These results show that the content of cobalt in the surface seawater at the location above is found to be $0.25 \pm 0.04 \mu \mathrm{g} / \mathrm{L}(n=5, P=0.95)$ with the recovery of about $96.9 \%-104 \%(n=4, P=0.95)$. These results are also in good agreement with the original concentrations found in the seawater samples as well as the added analyte concentrations. Furthermore, some other elements are newly detected as shown in Table 4. It is worthwhile mentioning here that in principle the added cobalt can be bound to 


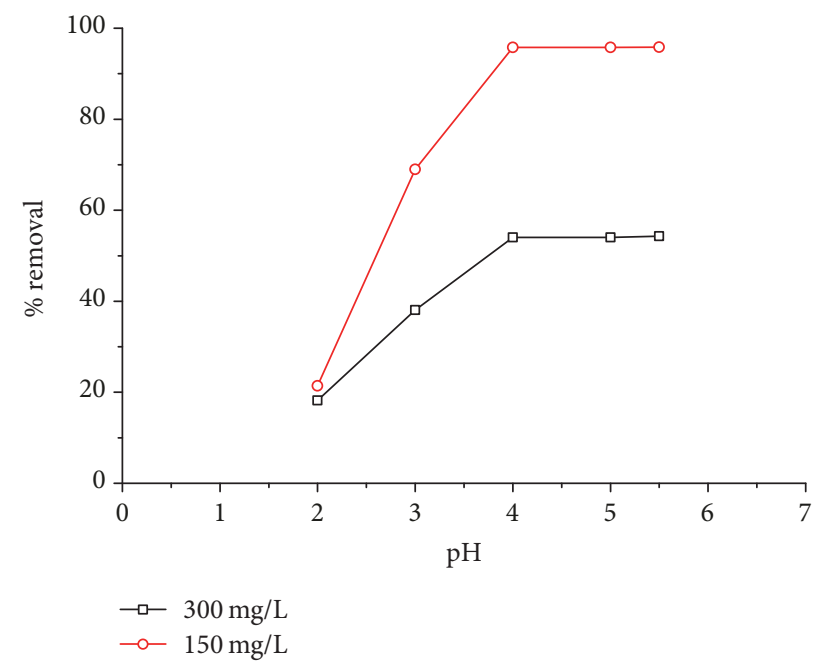

(a)

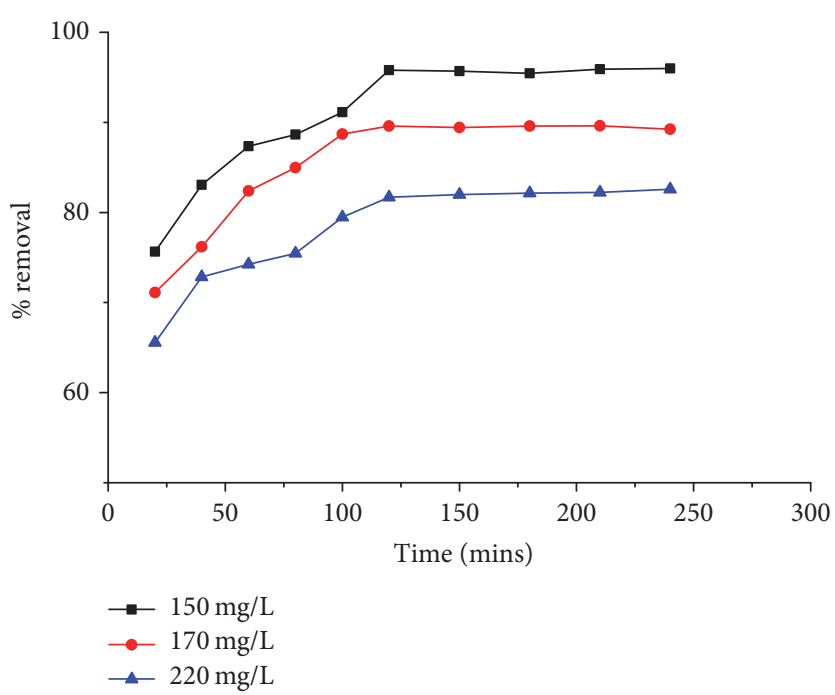

(b)

FIGURE 4: Effects of $\mathrm{pH}$ (a) and contact time (b) on the adsorption of $\mathrm{Co}(\mathrm{II})$ onto the $\gamma-\mathrm{MnO}_{2}$ nanomaterial at different initial concentrations of cobalt.

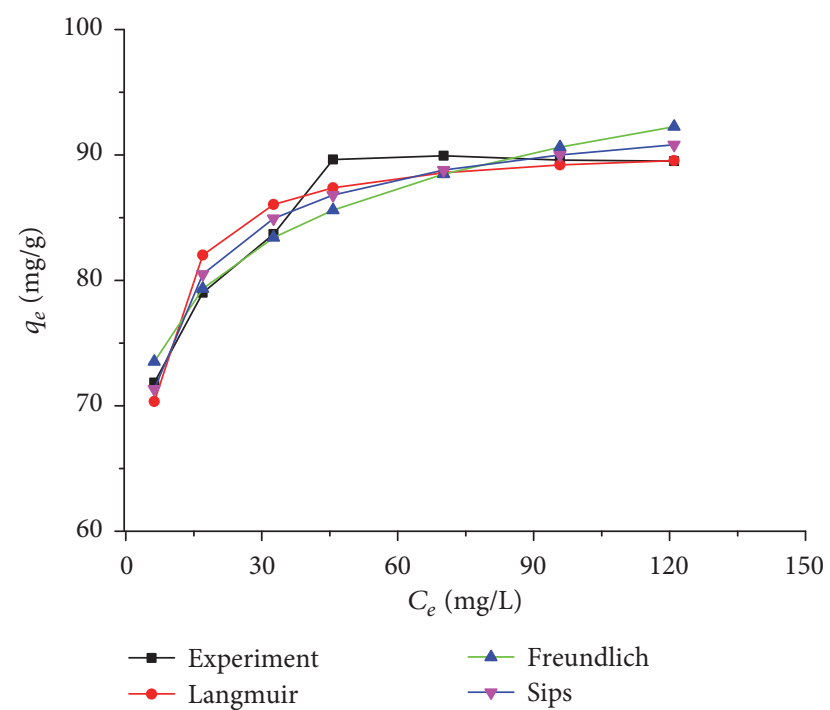

FIGURE 5: Plots of the adsorption capacity at the equilibrium $q_{e}$ versus the equilibrium concentration $C_{e}$ obtained within the Langmuir, Freundlich, and Sips nonlinear isotherm models.

make some particulate materials and/or dissolved organic ligands depending on the complexation kinetics and time for which the added cobalt can be exposed to the seawater. However, this effect, which might cause the change of the analytical results, is considered to be relatively small since the dissolubility of the solution used in the present study $(10-20 \mu \mathrm{g} / \mathrm{L})$ is rather high and the seawater samples before being analyzed are carefully filtered and acidified as described in Section 2.1.

3.5. Comparison with Other Studies. Table 5 presents the content of cobalt in seawater at some areas in the world determined by the same and/or different methods. It is found that the concentration of DCo in the surface seawater at

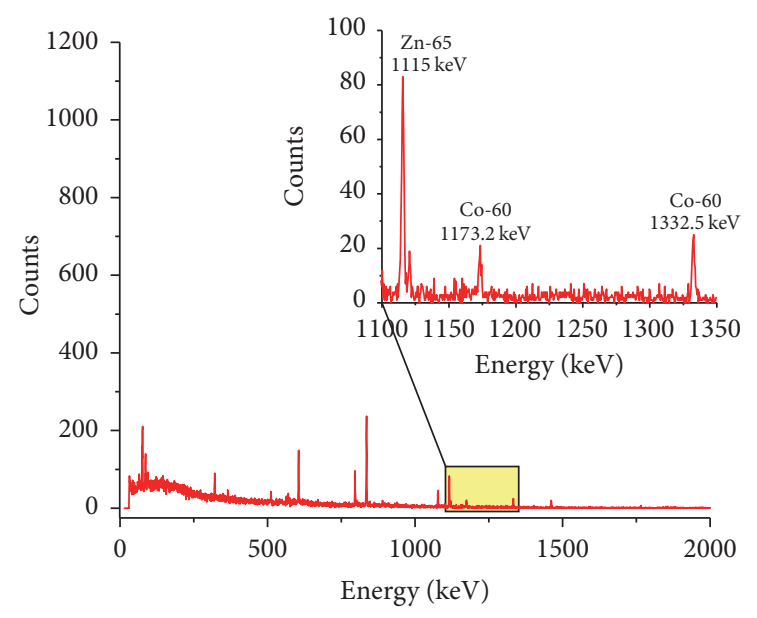

FIGURE 6: Gamma-ray spectrum of the $\gamma-\mathrm{MnO}_{2}$ nanomaterial before the adsorption of elements in the seawater.

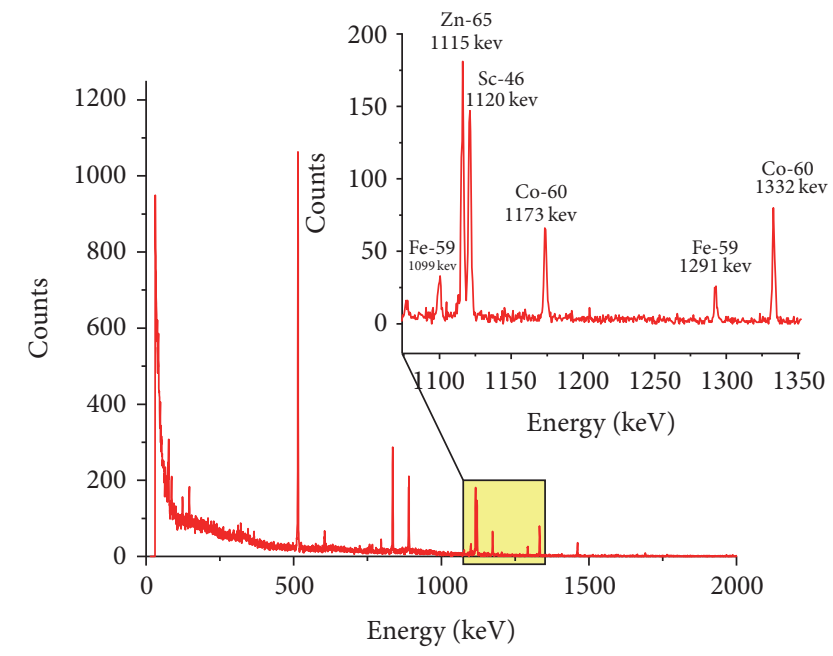

Figure 7: Same as Figure 6 but after the adsorption of elements in the seawater. 
TABLE 3: Analytical results for cobalt in seawater.

\begin{tabular}{lcccc}
\hline Element & $\begin{array}{c}\text { Co(II) added } \\
(\mu \mathrm{g} / \mathrm{L})\end{array}$ & Found $(\mu \mathrm{g} / \mathrm{L})$ & SD & Recovery $(\%)$ \\
\hline \multirow{3}{*}{ Cobalt } & 0 & $0.25 \pm 0.05(n=5, P=0.95)$ & 0.04 & 0.73 \\
& 10 & $10.1 \pm 1.16(n=4, P=0.95)$ & 0.68 & 98.80 \\
& 15 & $14.8 \pm 1.08(n=4, P=0.95)$ & 1.74 & 96.93 \\
\hline
\end{tabular}

SD: standard deviation.

TABLE 4: Elements found in seawater by using the NAA method.

\begin{tabular}{lcc}
\hline Elements & Found $(\mu \mathrm{g} / \mathrm{L})(n=5, P=0.95)$ & SD \\
\hline $\mathrm{Fe}$ & $213 \pm 18.9$ & 15.2 \\
$\mathrm{Zn}$ & $7.01 \pm 1.72$ & 1.38 \\
$\mathrm{Ce}$ & $1.92 \pm 0.23$ & 0.19 \\
$\mathrm{Sc}$ & $0.07 \pm 0.01$ & 0.008 \\
\hline
\end{tabular}

SD: standard deviation.

TABLE 5: Content of cobalt in the seawater at some areas in the world obtained within the same and/or different analytical methods. Here GFAAS and SF-ICP-MS stand for graphite furnace atomic absorption and sector field inductively coupled plasma mass spectrometers, respectively.

\begin{tabular}{lccc}
\hline Area & DCo $(\mu \mathrm{g} / \mathrm{L})$ & Analytical methods & Ref. \\
\hline Mediterranean Sea & 0.02 & SF-ICP-MS & GFAAS \\
Bosphorus & 4.28 & {$[19]$} \\
South East Atlantic & $0.30 \cdot 10^{-3}-3.48 \cdot 10^{-3}$ & Flow-Injection Analysis (FIA) and chemiluminescence & [CP-MS \\
Crozet Islands, Southern Ocean & $1.42 \cdot 10^{-3}-2.89 \cdot 10^{-3}$ & Chemiluminescence & {$[22]$} \\
Western Atlantic Ocean & $0.83 \cdot 10^{-3}-5.85 \cdot 10^{-3}$ & FIA with chemiluminescence & [23] \\
North Atlantic gyre, Atlantic Ocean & $1.38 \cdot 10^{-3}$ & FIA with chemiluminescence \\
South Atlantic gyre, Atlantic Ocean & $3.25 \cdot 10^{-3}$ & Ultrahigh resolution mass spectrometry \\
Angola Gyre, Atlantic Ocean & $0.71 \cdot 10^{-3}-9.74 \cdot 10^{-3}$ & NAA & [24] \\
Binh Thuan, Vietnam & 0.25 & This study \\
\hline
\end{tabular}

Binh Thuan coast, Vietnam, obtained within the present work is $0.25 \mu \mathrm{g} / \mathrm{L}$. This amount is higher than the results obtained from some different locations in the world such as Mediterranean Sea [19], South East Atlantic [21], Crozet Islands, Southern Ocean [22], Western Atlantic Ocean [23], North and South Atlantic gyre of Atlantic Ocean [24], and Angola Gyre of Atlantic Ocean [25], except the Bosphorus area [21] (see Table 5). The reason is that the seawater samples used in the present analysis are collected from the beach, which is located near the residential area that might cause the increase in the level of cobalt.

\section{Conclusions}

The neutron activation analysis method at the Dalat nuclear reactor (Vietnam) has been used to determine the concentration of dissolved cobalt in the seawater at Phan Thiet City, Binh Thuan Province, Vietnam, after the preconcentration by adsorption onto the $\gamma-\mathrm{MnO}_{2}$ nanomaterial. The concentration of dissolved cobalt in the surface seawater is found to be $0.25 \pm 0.04 \mu \mathrm{g} / \mathrm{L}(n=5, P=0.95)$ with the approximate recovery of $96.93 \%-104 \%(n=4, P=0.95)$. In addition, some elements and their concentrations have been newly determined, namely, Fe $(212 \mu \mathrm{g} / \mathrm{L}), \mathrm{Zn}(7.01 \mu \mathrm{g} / \mathrm{L})$, Ce $(1.92 \mu \mathrm{g} / \mathrm{L})$, and Sc $(0.07 \mu \mathrm{g} / \mathrm{L})$. All the results obtained show that the $\gamma-\mathrm{MnO}_{2}$ nanomaterial can indeed be used as an adsorbent to preconcentrate the trace elements from the water samples before being determined by the neutron activation analysis method.

\section{Conflicts of Interest}

The authors declare that there are no conflicts of interest regarding the publication of this paper.

\section{References}

[1] R. U. Shelley, B. Zachhuber, P. N. Sedwick, P. J. Worsfold, and M. C. Lohan, "Determination of total dissolved cobalt in UVirradiated seawater using flow injection with chemiluminescence detection," Limnology and Oceanography: Methods, vol. 8, no. JULY, pp. 352-362, 2010. 
[2] Q. Zhang, H. Minami, S. Inoue, and I. Atsuya, "Determination of ultra-trace amounts of cobalt in seawater by graphite furnace atomic absorption spectrometry after pre-concentration with Ni/8-quinolinol/1-nitroso-2-naphthol complex," Analytica Chimica Acta, vol. 407, no. 1-2, pp. 147-153, 2000.

[3] J. Bown, M. Boye, and D. M. Nelson, "New insights on the role of organic speciation in the biogeochemical cycle of dissolved cobalt in the southeastern Atlantic and the Southern Ocean," Biogeosciences, vol. 9, no. 7, pp. 2719-2736, 2012.

[4] C. E. Thuróczy, M. Boye, and R. Losno, "Dissolution of cobalt and zinc from natural and anthropogenic dusts in seawater," Biogeosciences, vol. 7, no. 6, pp. 1927-1936, 2010.

[5] M. R. Jamali, B. Soleimani, R. Rahnama, and S. H. A. Rahimi, "Development of an in situ solvent formation microextraction and preconcentration method based on ionic liquids for the determination of trace cobalt (II) in water samples by flame atomic absorption spectrometry," Arabian Journal of Chemistry, vol. 10, pp. S321-S327, 2017.

[6] Y. Wang, X. Ke, X. Zhou, J. Li, and J. Ma, "Graphene for separation and preconcentration of trace amounts of cobalt in water samples prior to flame atomic absorption spectrometry," Journal of Saudi Chemical Society, vol. 20, pp. S145-S152, 2016.

[7] S. Hirata, Y. Hashimoto, M. Aihara, and G. Vitharana Mallika, "On-line column preconcentration for the determination of cobalt in sea water by flow-injection chemiluminescence detection," Fresenius' Journal of Analytical Chemistry, vol. 355, no. 5-6, pp. 676-679, 1996.

[8] D. F. Schutz and K. K. Turekian, "The investigation of the geographical and vertical distribution of several trace elements in sea water using neutron activation analysis," Geochimica et Cosmochimica Acta, vol. 29, no. 4, pp. 259-313, 1965.

[9] J. M. Lo, K. S. Lin, J. C. Wei, and J. D. Lee, "Evaluation on chemical neutron activation analysis for trace metals in seawater using magnesium oxide as the preconcentration agent," Journal of Radioanalytical and Nuclear Chemistry, vol. 216, no. 1, pp. 121-124, 1997.

[10] E. Häsänen and P. Manninen, "Determination of total organic chlorine and bromine in water samples by adsorption onto activated carbon and neutron activation analysis," Chemosphere, vol. 16, no. 5, pp. 969-972, 1987.

[11] Y. Sakai, T. Tomura, K. Ohshita, and S. Koshimizu, "Determination of trace copper in water samples by neutron activation analysis preceded by preconcentration on activated carbon powder," Journal of Radioanalytical and Nuclear Chemistry, vol. 230, no. 1-2, pp. 261-263, 1998.

[12] H. A. Van Der Sloot, "The determination of chromium in water samples by neutron activation analysis after preconcentration on activated carbon," Journal of Radioanalytical Chemistry, vol. 37, no. 2, pp. 727-739, 1977.

[13] A. M. Yusof, M. M. Rahman, and A. K. H. Wood, "Speciation of some trace elements in water samples after preconcentration on activated carbon by neutron activation analysis," Journal of Radioanalytical and Nuclear Chemistry, vol. 259, no. 3, pp. 479484, 2004.

[14] M. T. Valentini Ganzerli, L. Maggi, and V. Caramella Cresp, "Preconcentration and neutron activation analysis of thorium and uranium in natural waters," Journal of Radioanalytical and Nuclear Chemistry, vol. 262, no. 1, pp. 143-146, 2004.

[15] U. Kerdpin, O. A. Arquero, R. Watanesk, and U. Sriyotha, "Manganese (II) adsorption stdudies on Aluminium oxide and Iron (III) oxide by neutron activation analysis," Journal of the Science Society of Thailand, vol. 24, pp. 73-80, 1998.
[16] J. Li, B. Xi, Y. Zhu, Q. Li, Y. Yan, and Y. Qian, “A precursor route to synthesize mesoporous $\gamma-\mathrm{MnO}_{2}$ microcrystals and their applications in lithium battery and water treatment," Journal of Alloys and Compounds, vol. 509, no. 39, pp. 9542-9548, 2011.

[17] N. C. Le and D. Van Phuc, "Sorption of lead (II), cobalt (II) and copper (II) ions from aqueous solutions by $\gamma-\mathrm{MnO}_{2}$ nanostructure," Advances in Natural Sciences: Nanoscience and Nanotechnology, vol. 6, no. 2, Article ID 025014, 2015.

[18] V. P. Dinh, N. C. Le, L. A. Tuyen, N. Q. Hung, V. D. Nguyen, and N. T. Nguyen, "Insight into adsorption mechanism of lead(II) from aqueous solution by chitosan loaded $\mathrm{MnO} 2$ nanoparticles," Materials Chemistry and Physics, vol. 207, pp. 294-302, 2018.

[19] G. Dulaquais, H. Planquette, S. L'Helguen, M. J. A. Rijkenberg, and M. Boye, "The biogeochemistry of cobalt in the Mediterranean Sea," Global Biogeochemical Cycles, vol. 31, no. 2, pp. 377399, 2017.

[20] O. G. Saglam and U. Koklu, "Atomic absorption spectrometric determination of cobalt and nickel after preconcentration by the application of chelate adsorption on amino-modified silica-gel," Journal of Trace and Microprobe Techniques, vol. 21, no. 2, pp. 249-257, 2003.

[21] J. Bown, M. Boye, A. Baker et al., "The biogeochemical cycle of dissolved cobalt in the Atlantic and the Southern Ocean south off the coast of South Africa," Marine Chemistry, vol. 126, no. 1-4, pp. 193-206, 2011.

[22] M. Castrillejo, P. J. Statham, G. R. Fones, H. Planquette, F. Idrus, and K. Roberts, "Dissolved trace metals (Ni, Zn, Co, Cd, Pb, Al, and $\mathrm{Mn}$ ) around the Crozet Islands, Southern Ocean," Journal of Geophysical Research: Oceans, vol. 118, no. 10, pp. 5188-5201, 2013.

[23] G. Dulaquais, M. Boye, R. Middag et al., "Contrasting biogeochemical cycles of cobalt in the surface western Atlantic Ocean," Global Biogeochemical Cycles, vol. 28, no. 12, pp. 1387-1412, 2014.

[24] R. U. Shelley, N. J. Wyatt, G. A. Tarran, A. P. Rees, P. J. Worsfold, and M. C. Lohan, "A tale of two gyres: Contrasting distributions of dissolved cobalt and iron in the Atlantic Ocean during an Atlantic Meridional Transect (AMT-19)," Progress in Oceanography, 2016.

[25] M. A. Saito, A. E. Noble, N. Hawco et al., "The acceleration of dissolved cobalt's ecological stoichiometry due to biological uptake, remineralization, and scavenging in the Atlantic Ocean," Biogeosciences, vol. 14, no. 20, pp. 4637-4662, 2017.

[26] S. Brunauer, P. H. Emmett, and E. Teller, "Adsorption of gases in multimolecular layers," Journal of the American Chemical Society, vol. 60, no. 2, pp. 309-319, 1938.

[27] M. Rafatullah, O. Sulaiman, R. Hashim, and A. Ahmad, "Adsorption of copper (II), chromium (III), nickel (II) and lead (II) ions from aqueous solutions by meranti sawdust," Journal of Hazardous Materials, vol. 170, no. 2-3, pp. 969-977, 2009.

[28] K. Y. Foo and B. H. Hameed, "Insights into the modeling of adsorption isotherm systems," Chemical Engineering Journal, vol. 156, no. 1, pp. 2-10, 2010.

[29] H. M. Dung and P. D. Hien, "The application and development of $\mathrm{k} 0$-standardization method of neutron activation analysis at Dalat research reactor," Journal of Radioanalytical and Nuclear Chemistry, vol. 257, no. 3, pp. 643-647, 2003.

[30] M. D. Ho, Q. T. Tran, V. D. Ho, D. V. Cao, and T. S. Nguyen, "Quality evaluation of the k 0-standardized neutron activation analysis at the Dalat research reactor," Journal of Radioanalytical and Nuclear Chemistry, vol. 309, no. 1, pp. 135-143, 2016. 
[31] E. P. Barrett, L. G. Joyner, and P. P. Halenda, "The determination of pore volume and area distributions in porous substances. I. Computations from nitrogen isotherms," Journal of the American Chemical Society, vol. 73, no. 1, pp. 373-380, 1951.

[32] W. C. Tsai, S. Ibarra-Buscano, C. C. Kan, C. M. Futalan, M. L. P. Dalida, and M. W. Wan, "Removal of copper, nickel, lead, and zinc using chitosan-coated montmorillonite beads in singleand multi-metal system," Desalination and Water Treatment, vol. 57, pp. 9799-9812, 2016.

[33] A. M. Cardenas-Peña, J. G. Ibanez, and R. Vasquez-Medrano, "Determination of the point of zero charge for electrocoagulation precipitates from an iron anode," International Journal of Electrochemical Science, vol. 7, no. 7, pp. 6142-6153, 2012.

[34] T. Mahmood, M. T. Saddique, A. Naeem, P. Westerhoff, S. Mustafa, and A. Alum, "Comparison of different methods for the point of zero charge determination of $\mathrm{NiO}$," Industrial \& Engineering Chemistry Research, vol. 50, no. 17, pp. 10017-10023, 2011.

[35] M. Gheju, I. Balcu, and G. Mosoarca, "Removal of Cr(VI) from aqueous solutions by adsorption on $\mathrm{MnO}_{2}$," Journal of Hazardous Materials, vol. 310, pp. 270-277, 2016.

[36] M. Singh, D. N. Thanh, P. Ulbrich, N. Strnadová, and F. Štěpánek, "Synthesis, characterization and study of arsenate adsorption from aqueous solution by $\alpha$ - And $\delta$-phase manganese dioxide nanoadsorbents," Journal of Solid State Chemistry, vol. 183, no. 12, pp. 2979-2986, 2010.

[37] Z. L. Zhu, H. M. Ma, R. H. Zhang, Y. X. Ge, and J. F. Zhao, "Removal of cadmium using $\mathrm{MnO}_{2}$ loaded D301 resin," Journal of Environmental Sciences, vol. 19, no. 6, pp. 652-656, 2007.

[38] Y. Ren, N. Li, J. Feng et al., "Adsorption of $\mathrm{Pb}$ (II) and $\mathrm{Cu}$ (II) from aqueous solution on magnetic porous ferrospinel $\mathrm{MnFe}_{2} \mathrm{O}_{4}$," Journal of Colloid and Interface Science, vol. 367, no. 1, pp. 415421, 2012.

[39] A. Heidari, H. Younesi, Z. Mehraban, and H. Heikkinen, "Selective adsorption of $\mathrm{Pb}(\mathrm{II}), \mathrm{Cd}(\mathrm{II})$, and $\mathrm{Ni}(\mathrm{II})$ ions from aqueous solution using chitosan-MAA nanoparticles," International Journal of Biological Macromolecules, vol. 61, pp. 251-263, 2013. 

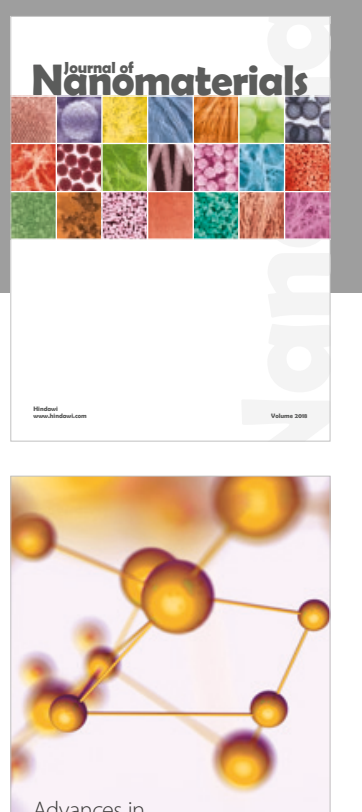

Physical Chemistry
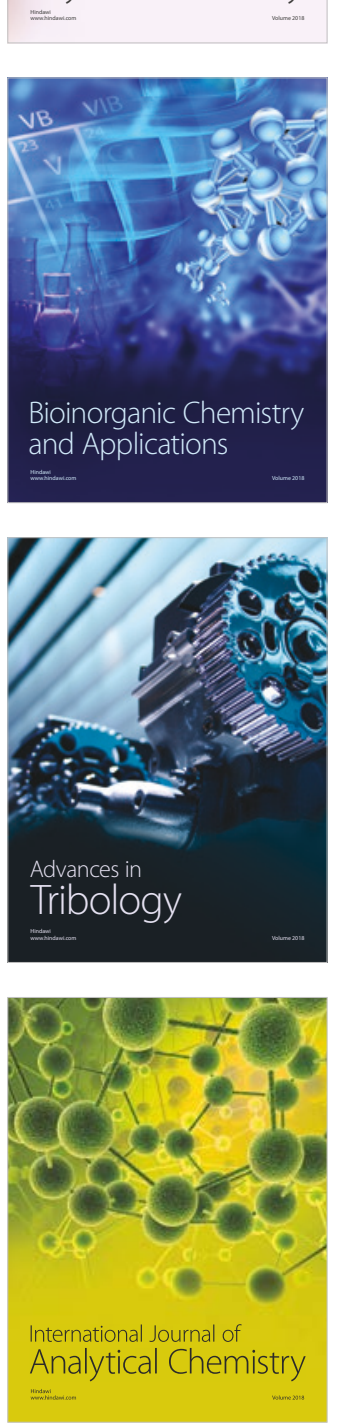

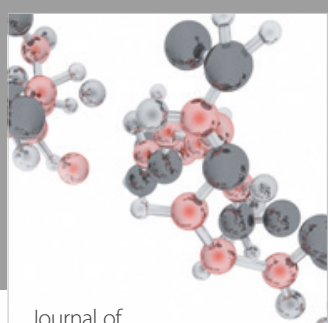

Analytical Methods

in Chemistry

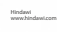

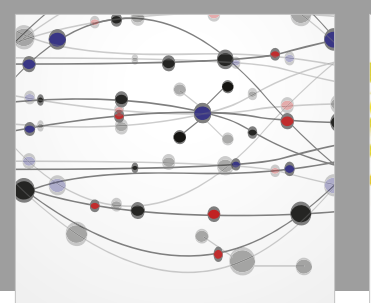

The Scientific World Journal

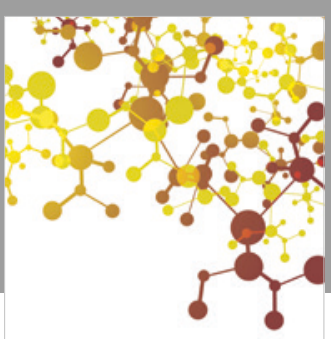

Journal of

Applied Chemistry
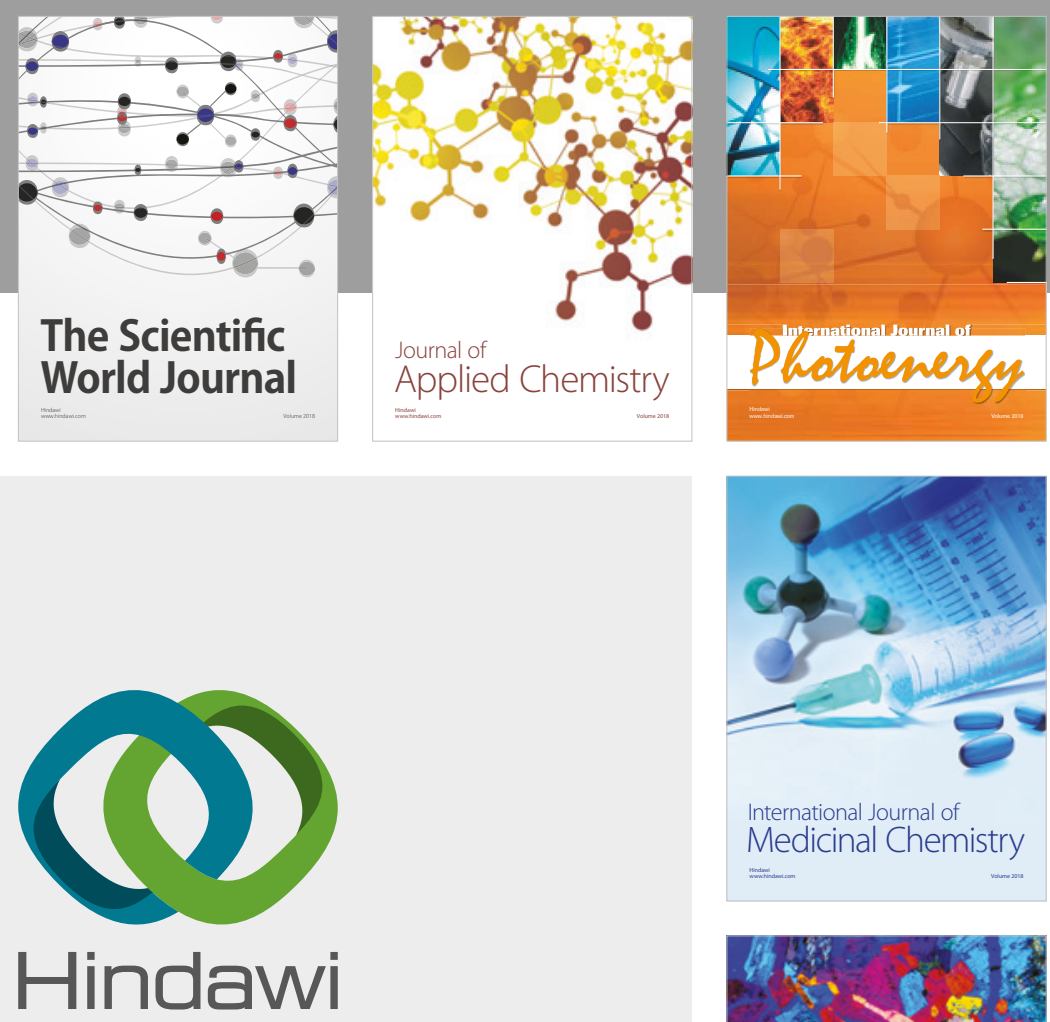

Submit your manuscripts at

www.hindawi.com
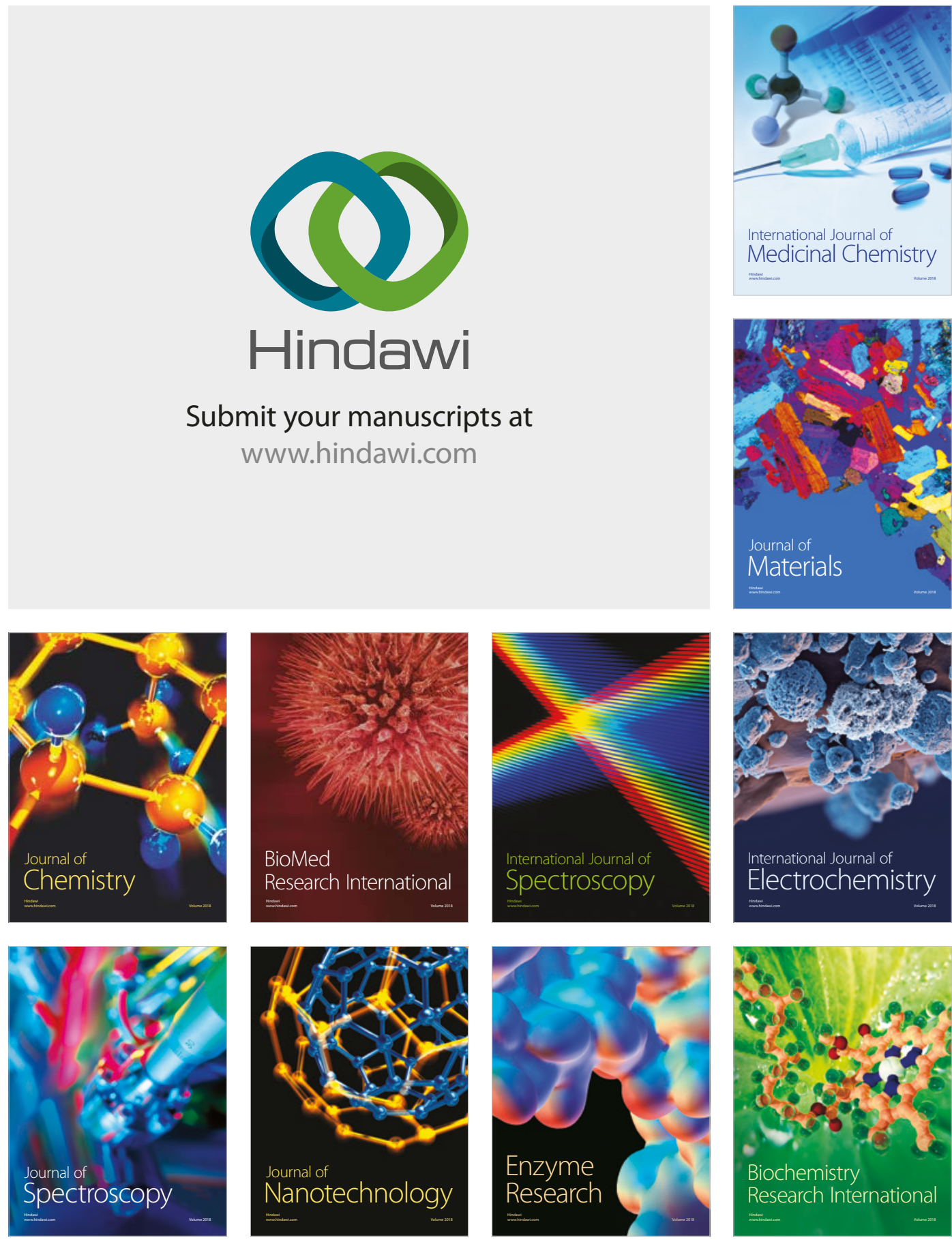
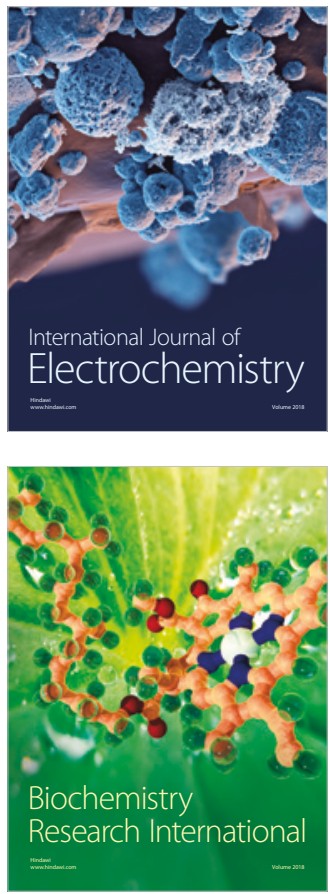